\title{
Las promesas de la modernidad puestas en juego: el sometimiento de la autonomía colectiva a libertad individual en el mercado ${ }^{1}$
}

\author{
Beatriz Silva Pinochet \\ Becaria Master en Investigación en Sociología. Universidad de Barcelona, Barcelona, España. Email: beatrizsilvapinochet@gmail.com
}

\begin{abstract}
Resumen: El proyecto de modernidad en la actualidad pone en contraposición y en lucha dos visiones de libertad que han estado presentes durante la Era Moderna, la libertad individual -que en este caso se manifiesta exclusivamente como acción en el mercado- y la autonomía colectiva. En nombre de ambas se han producido experimentos tanto para establecer la soberanía del pueblo (socialismo), como para someter totalmente la democracia a la acción individual, eliminando toda posibilidad de autonomía colectiva. Es este último experimento en el que nos encontramos hoy, el que, a pesar de haber recibido innumerables críticas tanto por su simplismo analítico (Lie, 1997), como por los desastrosos efectos sociales que ha provocado (Stiglitz, 1992: 12), sigue manteniendo su predominio a nivel mundial.
\end{abstract}

Palabras clave: libertad, democracia, modernidad

\section{Modernity promises at stake: subjugation of collective autonomy to individual freedom within the market}

\begin{abstract}
Current modernity project sets in opposition and struggle two visions of freedom that have been present during the Modern Era: individual freedom - as action in the market- and collective autonomy. Social experiments have been conducted in their name, both to establish people sovereignty (Socialism), as well as to completely subdue democracy to individual action, eliminating any possibility of collective autonomy. It is within this last experiment that we find ourselves living today, experiment that, despite being widely criticized for its analytical oversimplification (Lie, 1997), as well as for its disastrous social effects, has maintained its global hegemony (Stiglitz, 1992: 12).
\end{abstract}

Key words: freedom, democracy, modernity

\section{As promessas da modernidade posta em jogo: a sujeição da autonomia coletiva à liberdade individual no mercado}

\begin{abstract}
Resumo: O projeto da modernidade agora divide ordenadamente duas visões de luta pela liberdade que estiveram presentes durante a era moderna, a liberdade individual - que neste caso se manifesta apenas como uma ação no mercadoea autonomia coletiva. Em nome de ambos foram realizadas experimentos tanto para estabelecer a soberania do povo (o socialismo), como para levar totalmente a democracia a ação individual, eliminando qualquer possibilidade de autonomia coletiva. É este último experimento onde estamos hoje, que, apesar de ter recebido críticas maciças tanto pela sua simplicidade analítica (Lie, 1997), como pelos efeitos sociais desastrosos causados _ (Stiglitz, 1992: 12) consrgue manter sua dominação global.
\end{abstract}

Palavras-chave: liberdade, democracia, modernidade

$$
* * *
$$

\section{Modernidad: ideario y proceso}

La modernidad ha sido definida como una época que tiende hacia una creciente autonomía del individuo y del colectivo (Wagner, 2011). Un ideario esparcido desde la revolución francesa a distintas partes del mundo que levantó preceptos desarrollados durante la Ilustración, específicamente asociados a nociones de libertad y a la razón (Ibid: 14).

El ser humano (sólo el hombre en esos momentos), se liberó del sometimiento valórico de la religión y la monarquía y construyó la posibilidad de elegir a quienes lo gobernaban ${ }^{2}$. Las instituciones que desde allí surgieron supusieron la posibilidad de construir un orden racional en la sociedad. Supusieron también la apertura de posiciones sociales a quienes pudiera alcanzarlas. 
Fue el ascenso de la burguesía, la que, originalmente aliada con la monarquía, pero reconociendo que no podía restructurar el orden desde dentro, llevó a cabo una ruptura radical con el orden monárquico instituyendo el orden de la razón burguesa, la libertad burguesa y el comercio burgués, es decir el libre comrecio (Hobsbawn, 1971:18).

Durante ese periodo se fue gestando también un orden basado en la propiedad privada de los medios de producción. La religiosidad ligada al trabajo había logrado instalar una ética que posibilitó la racionalización de la actividad laboral (Weber, 1969), transformando con ello el status social de la burguesía al aceptarse socialmente dicha forma de adquirir riqueza. El éxito en el trabajo significaba la bendición del cielo y era un signo de salvación (Ibid).

La actividad comercial, a su vez, había empezado a ser bien vista en la medida que potenciaba las buenas relaciones entre países vecinos (Boltanski y Chiapello, 2002). El surgimiento de los estados nación unificó las fronteras y los comerciantes empezaron a encontrar menores barreras para la circulación de mercancías. La expansión del comercio burgués dio lugar a una ola de colonizaciones en una lucha imperialista por encontrar nuevos mercados (Arendt, 2006).

El surgimiento del capitalismo, como consecuencia de la libre circulación de la mano de obra y el consiguiente traslado a las ciudades de los campesinos antes atados a la tierra; el cercamiento de terrenos comunes que impidieron a los hombres -y sus familias- auto sustentarse, dañaron profundamente las relaciones sociales que caracterizaban a las sociedades de la época, lo que Polanyi denomina dislocación (Polanyi, 1992).

Por su parte, el predominio de ideas liberales que acompañó el desarrollo del capitalismo limitó la protección de las personas afectadas por estos procesos ${ }^{3}$. No obstante, a finales del siglo XIX y principios del XX el intervencionismo estatal remplazó al liberalismo de laissez faire que había causado profundos estragos sociales y económicos. Este remplazo se trató, para Polanyi, de un movimiento en defensa de la propia sociedad: la tesis del doble movimiento (Ibid: 200).

El surgimiento del comunismo y la fuerza que alcanzaron los sindicatos durante las primeras décadas del siglo XX, lograron que después de la primera guerra mundial se instauraran modelos de desarrollo más inclusivos (Wagner, 2011) que tendían hacia una mayor integración política, social y económica de las masas empobrecidas y excluidas totalmente de los beneficios del capital ${ }^{4}$.

De esta forma, durante la primera mitad del siglo XX se instaló una alianza, que empero no ha sido históricamente estable (Ibid: 99), ni siempre ideológicamente compatible (Polanyi, 1992: 286) ${ }^{5}$ entre el capitalismo y un sistema democrático representativo, el que suponía la coexistencia de la autonomía individual y una cierta autonomía colectiva, bajo la inclusión a nivel de votación y de libertad de asociación, de otros sectores sociales antaño excluidos ${ }^{6}$.

A pesar de la no necesaria coexistencia de los regímenes democrático-representativos y el sistema capitalista, la era industrial y la sociedad de masas hacen dependiente al capitalismo de la democracia, pues el incremento de la oferta de productos requiere de una masa consumidora que los demande, la que para participar; para someterse voluntariamente (Boltanski y Chiapello, 2002), requiere también de una promesa de inclusión material y simbólica ${ }^{7}$.

La democracia, sin embargo, impuso también sus límites a la autonomía colectiva. La ciencia política después de la segunda guerra mundial, se preocupó precisamente de establecerlos (Wagner, 2011: 104), de forma tal que la participación en el sistema democrático no trajera un cambio radical que transformara las instituciones ya establecidas, con lo cual se resguardaría también la modificación de las formas de propiedad.

Durante las décadas del 60 y 70, y a pesar de la alianza establecida entre trabajadores-consumidores y propietarios, bajo la estructura de sistema democrático y Estado-Nación, el capitalismo entra en una nueva crisis, de la que se salvaría gracias a una transformación tecnológica mayor, nacida según Boltanski y Chiapello (2002) gracias a la propia crítica libertaria anti capitalista y anti estado de mayo del '68. 
Este hecho producirá una transformación productiva -basada en la tecnología, innovación y la creatividad individual- de tal nivel que hace caer todas las nociones sobre modernidad, Estado-Nación, democracia y capitalismo. Dicho cambio tecnológico aliado con la teoría económica neoclásica (Wagner, 2011) ha producido la globalización de la economía y la implementación de políticas de corte neoliberal en numerosos lugares del mundo, lo que ha provocado una nueva desarticulación entre democracia y capitalismo (Ibid).

\section{Construcción política y libertad}

Según Arnsperger y Van Parjis (2009) la corriente filosófica libertarista ${ }^{8}$ es un componente radical de "lo que se ha convenido en llamar el neoliberalismo" y que tiene también su cuna en la escuela económica neoclásica. El libertarismo, aparece fuertemente en los años 70 y parte de la idea de "la dignidad fundamental de cada persona, que no puede ser burlada en nombre de ningún imperativo colectivo" (Ibid: 43). Desde la perspectiva libertarista las instituciones deben respetar y proteger los derechos fundamentales de los individuos: "el derecho de cada persona a la propiedad sobre sí misma, sobre las cosas que ha creado y sobre las que se ha convertido en legítima propietaria por apropiación originaria, por compra o donación”. (Ibid: 53). El Estado por ende, sólo debe resguardar que estos criterios se cumplan y no debe administrar ningún servicio, ni tener ninguna posesión, lo que sólo debe ser realizado por privados.

Las políticas económicas neoliberales operan bajo dicha noción de libertad, y han vuelto a levantar un concepto de mercado, de laissez faire, que había sido característico del capitalismo del siglo XIX ${ }^{9}$. Con esto levantan también un Nuevo Espíritu del Capitalismo -el tercer espíritu (Boltanski y Chiapello, 2002)-, el que sin embargo está débilmente fundado, debido a la imposibilidad de formular una crítica articulada y coherente, como lo fue la crítica hacia la sociedad de masas. Como efecto de este contexto, la versión actual de la promesa de modernidad juega más hacia la instauración de procesos que entreguen una autonomía individual -centrada en lo económico-, por sobre toda noción de autonomía colectiva.

La noción del bien común por su parte, necesaria para todo proyecto capitalista (Ibid), se constituye bajo la idea de la auto-regulación del mercado -la ficción comunista según Arendt (2009)- el que a través del equilibrio entre oferta y demanda lograría una articulación entre todos los beneficios individuales. Este hecho ha instalado de facto una democracia que sólo logra defender el principio de propiedad.

Este proceso ha significado también la total desaparición de la esfera pública (Ibid:43), es decir, la esfera del debate y discurso político entre ciudadanos, y su remplazo, ya no por la esfera social como lo fue durante la sociedad industrial ${ }^{10}$, sino por la esfera privada, la de la labor y el trabajo.

Para los griegos era en la esfera pública donde se podía ser verdaderamente libre, en tanto las necesidades biológicas y domésticas estaban resueltas en la esfera privada ${ }^{11}$. Era libertad en tanto se convivía con otros en la diferencia y no sólo en la suma de individualidades, que es lo que hace distinto a lo político de lo social (Arendt, 1997: 20).

No obstante, el capitalismo, como vertiente de la modernidad, y sus principios de productividad económica, ha rechazado esta actividad cuyos beneficios no pueden ser medidos en términos monetarios, sino como contraproducentes al tiempo dedicado a la generación de valor económico. La era moderna, según Hannah Arendt ha rechazado siempre esta esfera y citando a Adam Smith quién habla de "esa no próspera raza de hombres comúnmente llamada hombres de letras" (Arendt, 2009:65), asume para este período, la desaparición del espacio de libertad e igualdad en que se constituyó la Polis.

Se pierde con ello el objetivo liberador de la política y la posibilidad de construcción de autonomía colectiva en el espacio público, no como suma de individualidades sino como construcción de discurso y realidad en el debate y la acción: "La autonomía de la colectividad, que no puede realizarse sino a través de la auto-institución y el autogobierno explícitos, es inconcebible sin la autonomía efectiva de los individuos que la componen. [...] Pero lo contrario es igualmente verdadero: la autonomía de los individuos es inconcebible e imposible sin la autonomía de la colectividad [...] para lo que es necesario participar efectivamente de la formación de las leyes" (Castoriadis, 1994:52). 
La actual época post sociedad industrial ha profundizado este proceso ya diagnosticado por Arendt, dado que no sólo ha dejado de existir la esfera pública ${ }^{12}$, sino también el interés privado ha dejado de pertenecer a la esfera social. Lo que existe es la libertad en lo privado, la libertad de acumular riquezas, que durante la modernidad se vuelve de interés público (Arendt, 2009). Esta pasa a ser predominante, por sobre toda noción de autonomía colectiva y democracia: "los hombres se han convertido en completamente privados, es decir, han sido desposeídos de ver y oír a los demás, de ser vistos y oídos por ellos. Todos están encerrados en la subjetividad de su propia experiencia singular, que no deja de ser singular si la misma experiencia se multiplica innumerables veces. El fin del mundo común ha llegado cuando se ve sólo bajo un aspecto y se le permite presentarse únicamente bajo una perspectiva." (Ibid: 67).

A pesar de que este contexto, según Boltanski y Chiapello (2002), pareciera surgir de una crítica emancipatoria en contra de la sociedad de consumo y del sistema democrático representativo basado en el Estado de bienestar, esta crítica no ha traído consigo la unidad de un sujeto ajeno al Estado y al mercado, si bien las nociones de sociedad civil apuntan en ese sentido.

Ha traído consigo una noción de libertad individual, principalmente entendida como acción en el mercado $^{13}$ y la desafección con la política, o "liberal society and citizen disaffection" (Wagner, 2011:109), además de la absoluta imposibilidad del colectivo de demandar regulaciones a la acumulación y al proceso de producción, que cada vez se desligan en mayor medida del Estado-Nación. Desde la perspectiva de Castoriadis, "la crisis de los imaginarios que se refieren a las finalidades de la vida colectiva", hacen de la democracia un "mero conjunto de «procedimientos»" (Castoriadis, 1994:50), que no tienen más utilidad que mantener la inercia de un sistema en que el colectivo no decide sobre los procesos que le afectan.

A pesar de que en la última década y especialmente en último año se ha empezado a hacer evidente una crítica de parte de movimientos sociales que apelan a una democracia más plena, esta vez sí bajo la noción de esfera pública como espacio de debate, y también como demanda hacia la permanencia de ciertos aspectos de la esfera privada (salud, economía, educación) como interés público (esfera social), todavía no es posible distinguir cómo este proceso puede conllevar un nuevo compromiso con la autonomía colectiva.

\section{Chile Actual: páramo de la democracia y paraíso del mercado ${ }^{14}$}

Si bien los procesos mencionados tienen como origen el continente europeo, el mundo entero y América Latina en especial no han sido ajenos a ellos. Más aún; en Chile específicamente se han realizado experimentos que han intentado aplicar de forma más o menos ortodoxa distintas promesas de modernidad o bien, diferentes proyectos de modernización ${ }^{15}$.

Pasando por los proyectos desarrollistas, la inclusión de las masas proletarias en el proyecto nación ${ }^{16}$, la nacionalización y posterior estatización del cobre, la reforma agraria, etc. desde finales del siglo XIX y durante el siglo XX se intentó dotar a la sociedad chilena de los aspectos que harían de ella una sociedad moderna y desarrollada: racionalidad en la producción, generación de una burguesía industrial ${ }^{17}$, inclusión social, democracia de masas ${ }^{18}$.

Por su parte, la vía chilena al socialismo y la consiguiente implementación de políticas neoliberales durante la dictadura ${ }^{19}$, pusieron en contraposición dos nociones de libertad: autonomía colectiva y libertad individual respectivamente, esta última específicamente orientada al mercado ${ }^{20}$. Durante el primer experimento todo ámbito de la vida se politizó y pasó a ser parte de la esfera pública. Se proyectó la construcción del "hombre nuevo" por lo que cada aspecto de la esfera privada (desde el trabajo hasta las relaciones de familia) se problematizó y se convirtió en objeto de discusión.

Durante el segundo experimento, calificado por Emir Sader como el más neoliberal dentro de la región más neoliberal del mundo (Cornejo, 2007:2), la esfera pública es asumida como un espacio de construcción inútil. La esfera privada, la del trabajo y de la producción de riqueza toma el lugar de lo público, mientras que la de la familia se vuelve hacia la esfera social, debido a la imposición de valores que limitan la libertad individual que no sea netamente económica. 
Con el fin de limitar la democracia, en tanto la democracia no es un fin en sí mismo (Guzmán, 1991:332) y amparar la libertad individual en el mercado, el gobierno de Pinochet ideó todo un aparato institucional que impidiera la transformación y resguardase el orden ${ }^{21}$ : "En otras palabras, en vez de gobernar para hacer, en mayor o menor medida, lo que los adversarios quieren, resulta preferible contribuir a crear una realidad que reclame de todo el que gobierne una sujeción a las exigencias propias de ésta. Es decir, que si llegan a gobernar los adversarios, se vean constreñidos a seguir una acción no tan distinta a la que uno mismo anhelaría" (Ibid: 377)

El discurso político de los gobiernos de la Concertación y del gobierno actual ha mantenido el compromiso con estos principios, abogando por soluciones técnicas y por la aplicación de criterios específicos para cada ámbito de la sociedad, pero no para la sociedad en su conjunto. La libertad individual en el mercado y la autorregulación del mismo se defienden por su carácter técnico, que sería ajeno a intereses ideológicos. Como consecuencia, se rechazan respuestas "populistas" a las demandas sociales y se vela por la "gobernabilidad", en tanto la sola operación del mercado debería hacer avanzar a la sociedad hacia el desarrollo (noción de bien común).

Desde esta perspectiva, se percibe que las presiones colectivas que pretenden fortalecer el rol regulador del Estado o que abogan hacia una redistribución de los ingresos no comprenderían los efectos que estas demandas tendrían sobre la economía y el desarrollo, limitando la eficiencia de la acción privada o la acumulación de la riqueza que permite la inversión. No entenderían por tanto los límites que estas demandas imponen a la libertad"22 : "Si queremos una democracia auténticamente libertaria, y no estatista o socializante, es menester arraigar en los chilenos el ejercicio de las libertades económico-sociales, identificadas con los derechos cotidianos que más gravitan en la efectiva decisión de cada persona respecto de su destino personal y familiar.” (Guzmán, 1991:438)

Como consecuencia de este proceso, la esfera social, es decir, el interés público por la esfera privada, más allá de lo que refiere a la acumulación de riqueza, desaparece. El Estado deja de ser responsable de los destinos individuales, que pasan a depender del mercado. Toda oferta específica de servicios ahora privatizados genera un público objetivo separado por capacidad de pago y/o por estilo de vida (ideología, etnia, religión, clase) que actúa en forma separada, que aprende en forma separada, que no se reúne con otros en situación de igualdad -en la diferencia- y en ningún espacio que no esté de antemano sometido a relaciones de poder.

Sin embargo, la emergencia de los estudiantes en 2011 ha venido generando una crítica social (Boltanski y Chiapello, 2002) que exige, entre otros aspectos, la ampliación de la autonomía colectiva. Han presentado una demanda referida tanto a la importancia del rol regulador del Estado sobre aspectos privados de interés público (educación, salud), como hacia otorgar nuevamente valor a la política como herramienta mediante la cual la sociedad debate y define sus prioridades ${ }^{23}$ (Silva, 2007).

Así lo expresa Camila Vallejo cuando al inicio de la movilización estudiantil de 2011 responde al actual ministro del interior, Rodrigo Hinzpeter, quién había calificado el movimiento estudiantil como un movimiento politizado: "Queremos que Hinzpeter entienda que esto es un movimiento político, que ha tenido una maduración importante, que estamos peleando para tener una mejor educación y pensamos en el desarrollo del país" ${ }^{24}$. Asimismo, lo expresa la exigencia por un Estado más presente y regulador de las relaciones entre sociedad y mercado.

La apatía política de los jóvenes de los 90, los "no estoy ni ahí” 25 , contrasta con el actual compromiso de los estudiantes por lo social y lo público. El mito respecto de la falta de interés de la juventud en lo público, ha sido roto por las distintas movilizaciones estudiantiles que se han venido dando principalmente desde el 2001, con "el mochilazo", la Revolución Pingüina y actualmente con la movilización estudiantil universitaria y secundaria.

En términos de la tesis del doble movimiento (Polanyi, 1992), la sociedad, a través de estas acciones, se defiende de los efectos dislocadores de una excesiva introducción del mercado en diversos aspectos de la vida (mercantilización). No obstante, como señala Wagner (Wagner, 2011) "una democracia intensa inclusiva y con altos niveles de deliberación y participación- se levanta en una tensión de principios con el 
capitalismo y tal vez incluso con el discurso de la modernidad económica en general” (Wagner, 2011:112, traducción propia).

\section{Notas}

${ }^{1}$ El presente texto forma parte de reflexiones en torno a los procesos históricos vividos por Chile, principalmente durante las últimas décadas, y en especial sobre el significado que ha tenido el movimiento estudiantil desde el año 2006 como respuesta al período postdictadura. Constituye una primera aproximación al proyecto de tesina para el Master en Investigación en Sociología de la Universidad de Barcelona.

${ }^{2}$ Inicialmente, el régimen construido en Francia después de la Revolución Francesa "expresaría la voluntad general del «pueblo»" (Hobsbawn, 1971:115) Sin embargo, según Hobsbawn el liberal burgués de la época no era demócrata, sino "un creyente en el constitucionalismo, en el Estado secular con libertades civiles y garantías para la iniciativa privada, gobernado por contribuyentes y propietarios" (Hobsbawn, 1971:115).

${ }^{3}$ Según Polanyi, hay autores que indican que la protección entregada en Inglaterra para proteger a los campesinos que eran expulsados del campo a las ciudades (la Ley de Pobres), evitó que en ese país se diera una revolución tan radical como la Francesa (Polanyi, 1992:145). No obstante, las ideas liberales primaron una vez derogadas estas leyes, después de lo cual, según este autor, nace verdaderamente la clase trabajadora moderna y el capitalismo industrial (Polanyi, 1992:153).

${ }^{4}$ En el contexto de la guerra fría, y a nivel latinoamericano la implementación de políticas más inclusivas (al menos en el discurso), también se concibió como una fórmula para evitar un mayor avance del comunismo. Éstas intentaron además la transformación productiva desde un capitalismo agrario y exportador de materias primas, hacia un capitalismo desarrollista, todo esto acompañado por la creación de la Alianza para el Progreso.

${ }^{5}$ Polanyi señala que la inclusión de la clase trabajadora en el sistema democrático fue negada en Inglaterra durante muchos años. Los economistas liberales, por su parte, estaban convencidos de que la democracia popular era un peligro para el capitalismo (Polanyi, 1992:286), es decir para la libertad económica y la propiedad.

${ }^{6} \mathrm{El}$ avance de los valores propuestos por la modernidad, tanto en su vertiente democratizadora como capitalista y en lo que implica la asociación entre los valores que ambos sistemas propugnan, pueden originar compromisos diferentes, según señala Peter Wagner, además de distintas formas de interpretar los procesos de modernización (Wagner, 2011:34).

${ }^{7}$ Esta inclusión, en muchos casos y especialmente en América Latina, también fue exigida por las masas de trabajadores, a la vez que fue reprimida violentamente. La modernidad como posibilidad de ruptura con el orden impuesto, como igualación formal de los derechos de todos los miembros de una nación, también logró movilizar a los pobres en procesos de autoprotección y demanda.

${ }^{8}$ El término "libertarianism" ha sido traducido como libertarismo, pero también como libertarianismo. Cabe distinguir sin embargo, entre el libertarianismo o libertarismo asociado a la filosofía que valora por sobre todo la libertad individual, y que mantiene una posición en que reafirma la propiedad privada -lo que es compartido tanto por libertarianos de derecha como de izquierda difiriendo respecto de cómo ambos piensan que la propiedad debe ser adquirida en primera instancia-, de, por otra parte, otros movimientos también denominados libertarios, que se oponen al capitalismo.

${ }^{9}$ Cabe destacar, no obstante, que si bien el neoliberalismo actúa bajo una noción de libertad en lo económico, en la práctica se ha asociado a un conservadurismo valórico que limita la libertad individual fuera del mercado.

${ }^{10}$ En la era industrial, el Estado-Nación empezó a administrar aspectos de la vida que antes correspondían exclusivamente el dominio privado, como la economía, lo que funde el interés privado en lo público (esfera social) (Arendt, 2009:45). Según Arendt esto sucede por primera vez cuando una organización de propietarios pide protección para acumular más riqueza, en lugar de solicitar el acceso a la esfera pública debido a su riqueza (Arendt, 2009:73).

${ }^{11}$ Esta referencia va dirigida atender la noción de polis en su aspecto de lugar de encuentro y debate, excluyendo el hecho de que la libertad en la polis tenía como precondición la existencia de desigualdades. La dominación de los esclavos o de la mujer en la esfera privada implicaba resolver las necesidades domésticas, lo que permitía alcanzar la libertad entre pares (Arendt, 2009:45).

${ }^{12}$ Para Castoriadis la esfera pública pasa a ser privada en tanto "las decisiones verdaderamente importantes se toman en la trastienda (del Gobierno, del Parlamento, de los partidos)". (Castoriadis, 1994:53)

${ }^{13} \mathrm{Si}$ bien el desarrollo de la libertad individual se entiende como el incremento de la autonomía del individuo en todos los ámbitos, el predominio del neoliberalismo ha significado un énfasis en una idea de libertad principalmente asociada a lo económico.

${ }^{14}$ El subtítulo hace referencia a la primera parte del libro de Tomás Moulian, Chile Actual: anatomía de un mito (Moulian, 1997), llamada El Chile Actual: Páramo del Ciudadano, Paraíso del Consumidor.

${ }^{15}$ Según Moulian (Moulian, 1997:17) nuestra sociedad ha estado obsesionada "por una modernización que alegremente confunde con modernidad". 
${ }^{16}$ Desde la primera guerra mundial en Chile se produce una asociación entre una mayor intervención del Estado en el ámbito económico y procesos de democratización que derivaron en la generación de una matriz estado-céntrica, la que predominó entre los años 1940 y 1970. (Muñoz, 1994:52).

${ }^{17}$ Fue el Estado el que tomó el rol de potenciar una burguesía industrial inexistente en Chile generando, según Cecilia Montero (Montero, 1994:56) un empresariado dependiente del Estado que se vuelve más autónomo durante el Gobierno de Frei Montalva y de la Unidad Popular, a medida que empiezan a sentir que el Estado ya no da respuesta directa a sus demandas. Es por eso que más tarde éste se auto organiza para solicitar la intervención de las FF.AA. en defensa de la propiedad privada, lo que no implica que durante la dictadura el empresariado tome el poder. Más bien, se le entrega el poder a una nueva tecnocracia representada por los denominados Chicago Boys, quiénes implementaron políticas neoliberales tendientes a la modernización (las siete modernizaciones) de la economía y el Estado.

${ }^{18}$ Estos procesos también estuvieron cargados de "los conceptos de movimiento" que según Habermas surgen con la expresión «época moderna» y su ruptura con el pasado y que han seguido manteniendo su vigencia hasta hoy: revolución, progreso, emancipación, desarrollo, crisis, espíritu de la época (Habermas, 1989:18). Recordemos en asociación con esto la "Revolución en libertad" de Frei Montalva, la "vía chilena al socialismo" de la Unidad Popular y la Revolución Silenciosa (Lavín, 1988) que habría desarrollado la dictadura a través de las transformaciones estructurales.

${ }^{19}$ Éstas tuvieron una aplicación ortodoxa en un principio para después suavizarse luego de la crisis del 82 (Montero, 1994:59).

${ }^{20}$ Según Francisco Ignacio Pyret los principios neoliberales fueron adoptados más tarde por los opositores al Régimen Militar, motivo por el cual las FF.AA. consienten en pactar con ellos el traspaso del Gobierno. La participación en el plebiscito del 88, que asumía una aceptación implícita de la Constitución del 80, fue también una aceptación -por parte de la oposición- a las reglas y marcos institucionales impuestos por la dictadura, estableciendo las bases para la "democracia de los acuerdos".

${ }^{21}$ El golpe de Estado de 1973, apoyado por EE.UU. no tajo consigo, como sí lo hizo en algunos países de Asia cuyos modelos de desarrollo también contaron con la venia y el apoyo de EE.UU., un capitalismo dirigista que, a pesar de la represión, entregara importantes beneficios sociales a los trabajadores (Castells, 2003). La vertiente neoliberal de esta nueva fase del capitalismo tendió hacia la implementación de un capitalismo de Estado focalizado y descentralizado, lo que ha implicado también la transformación de servicios en bienes de consumo y con ello ha privatizado toda la oferta sanitaria y educativa que antes era de carácter estatal (la esfera social ha dejado lugar sólo a la esfera privada).

${ }^{22}$ Como se mencionó anteriormente, la oposición a la dictadura no pone en duda la noción de libertad impuesta por ésta. La protección a la libertad económica como principio fundamental se resume en el siguiente párrafo de Edgardo Böninger, quién el año 1984 se preguntaba cómo facilitar el traspaso de un gobierno militar a un gobierno elegido: "Gradualidad en el cambio económico y social, de suerte de obtener el beneplácito de las FF.AA., las élites capitalistas y los inversionistas extranjeros, logrando "la superación de la pobreza y una progresiva disminución de las desigualdades, sin menoscabo de la dimensión económica de la libertad". (Pyret, 1994:77)

${ }^{23}$ Ya durante el movimiento estudiantil del 2006 (Revolución Pingüina y también en movilizaciones anteriores, pero que no tuvieron la presencia que tuvo esta movilización, es posible distinguir un discurso de parte de los estudiantes que hace referencia a la necesidad de fortalecer el rol del Estado por sobre el mercado, que hace alusión al significado de lo público en asociación al Estado y a lo público como lugar de encuentro (esfera pública), apelando a la renovación de las dinámicas políticas que caracterizan a la democracia.

${ }^{24}$ Fuente: http://www.emol.com/noticias/nacional/2011/06/30/490050/minuto-a-minuto-masiva-marcha-estudiantil-concluye-condetenidos-e-incidentes-aislados-finalizado.html

${ }^{25} \mathrm{La}$ apatía de los jóvenes durante la década de los 90, en la etapa de "transición a la democracia", fue generalmente interpretada como una característica intrínseca de las nuevas generaciones y de las actuales democracias, que no concitarían mayor compromiso.

\section{Bibliografía}

Arendt, Hannah (2009), La Condición Humana, Paidós, Buenos Aires.

Ídem (2006), Los Orígenes del Totalitarismo, Alianza Editorial, Madrid.

Arendt, Hannah (1997), Qué es la política, Ediciones Paidós, Barcelona.

Arnsperger, Christian, Van Parijs Philippe (2009), Ética Económica y Social, Teorías de la Sociedad Justa”, Paidós, Barcelona.

Boltanski, Luc, Chiapello, Eve (2002) The New Spirit of Capitalism, Verso, Londres.

Castells, Manuel (2003) La Era de la Informació: economía, sociedad i cultura, UOC, Barcelona.

Castoriadis, Cornelius (1994), "La Democracia como procedimiento y como Régimen", disponible en: dialnet.unirioja.es/servlet/dcfichero_articulo?codigo=174662 
Cornejo, Rodrigo (2007), "Participación e incidencia de la sociedad civil en las políticas educativas: El caso chileno", Foro Latinoamericano de Políticas Educativas, Buenos Aires.

Díaz, Álvaro (1994), "Dinámicas del Cambio Tecnológico en la Industria Chilena. Desafíos para la Década de los 90”, Proposiciones N²4, Ediciones Sur, Santiago de Chile.

Guzmán, Jaime (1991), "El miedo y otros escritos: el pensamiento de Jaime Guzmán”, compilado por Arturo Fontaine, en Serie Estudios Públicos No 42, Centro de Estudios Públicos (CEP), Santiago de Chile.

Habermas, Jürgen (1989), El Discurso Filosófico de la Modernidad, Taurus, Madrid.

Hobsbawn, Erick (1971), Las Revoluciones Burguesas, Guadarrama, Madrid.

Lavín, Joaquín (1988), Chile: la revolución silenciosa, Zig-Zag, Santiago de Chile.

Lie, John (1997), “Sociology of Markets”, en Annual Review of Sociology, Vol. 23, pp. 341-360, Revista de la Universidad de California.

Montero, Cecilia (1994), "Empresarios, Estado y Desarrollo: una perspectiva histórica”, Proposiciones ํ24, Ediciones Sur, Santiago de Chile.

Moulian, Tomás (1998), Chile actual: anatomía de un mito, LOM Arcis, Santiago de Chile.

Muñoz, Óscar, (1994), "El nuevo rol del Estado en el desarrollo económico neoliberal”, Proposiciones №24, Ediciones Sur, Santiago de Chile.

Ortega, Luis (1994), "Los límites de la modernización en Chile: siglo XIX y XX”, Proposiciones N $^{\circ} 24$, Ediciones Sur, Santiago de Chile.

Pyret, Fernando Ignacio (1994), "Equilibrios Macroeconómicos y Pobreza en Chile", Proposiciones N²4, Ediciones Sur, Santiago de Chile.

Polanyi, Karl (1992), La Gran Transformación, Fondo de Cultura Económica, Buenos Aires.

Silva, Beatriz (2007), La Revolución Pingüina y el cambio cultural en Chile, CLACSO, Buenos Aires, disponible en: http://bibliotecavirtual.clacso.org.ar/ar/libros/becas/2007/cultura/silva.pdf

Stanford Encyclopedia of Philosophy, disponible en: http://plato.stanford.edu/

Wagner, Peter (2012), Modernity: understanding de present, Polity Press, Inglaterra.

Weber, Max (1969), La Ética Protestante y el Espíritu del Capitalismo, Península, Barcelona.

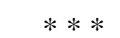

Recibido: 15.02 .2012

Aceptado: 11.03.2012 